The Library's Place in a Mobilé Q. o space

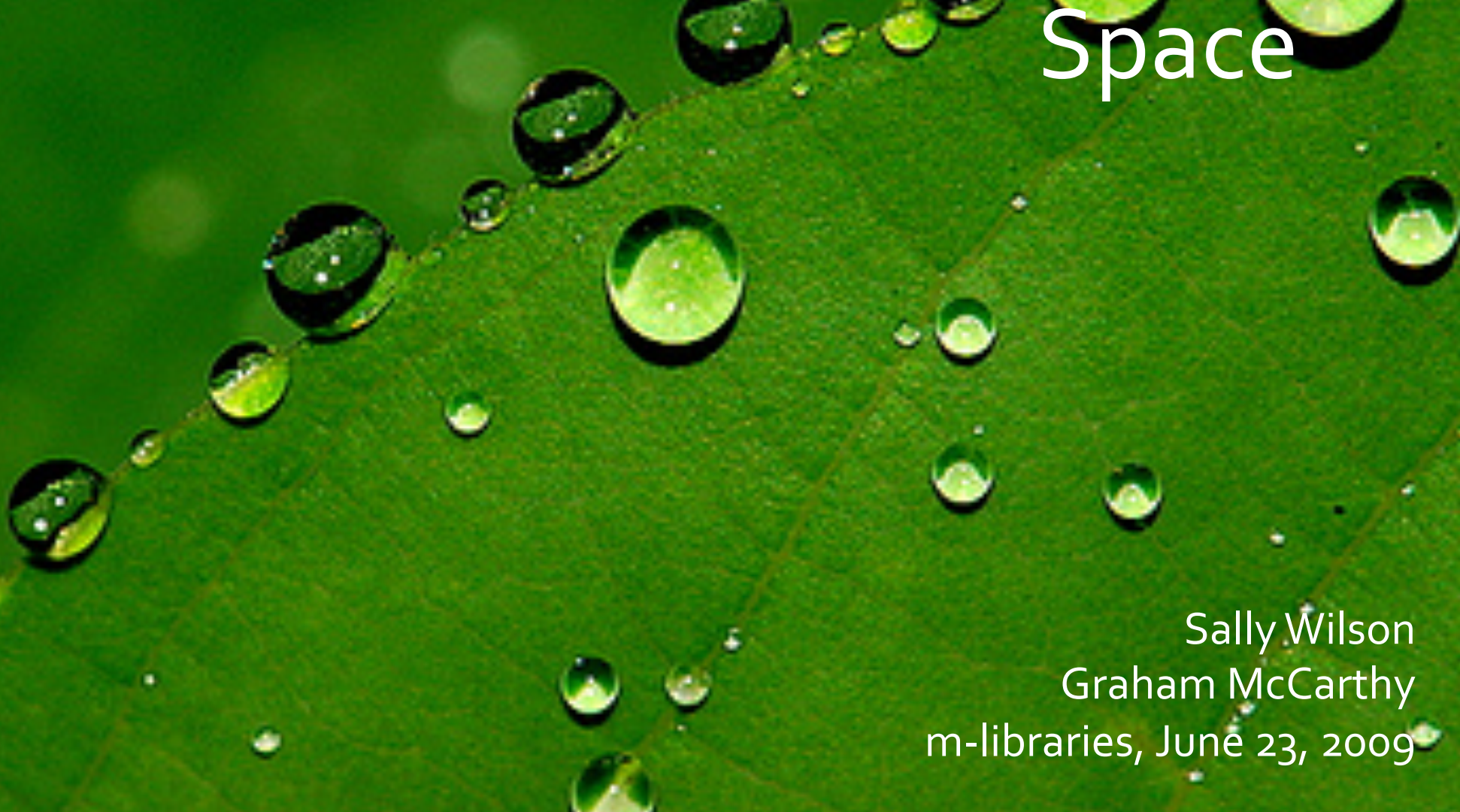




\section{Take Aways}

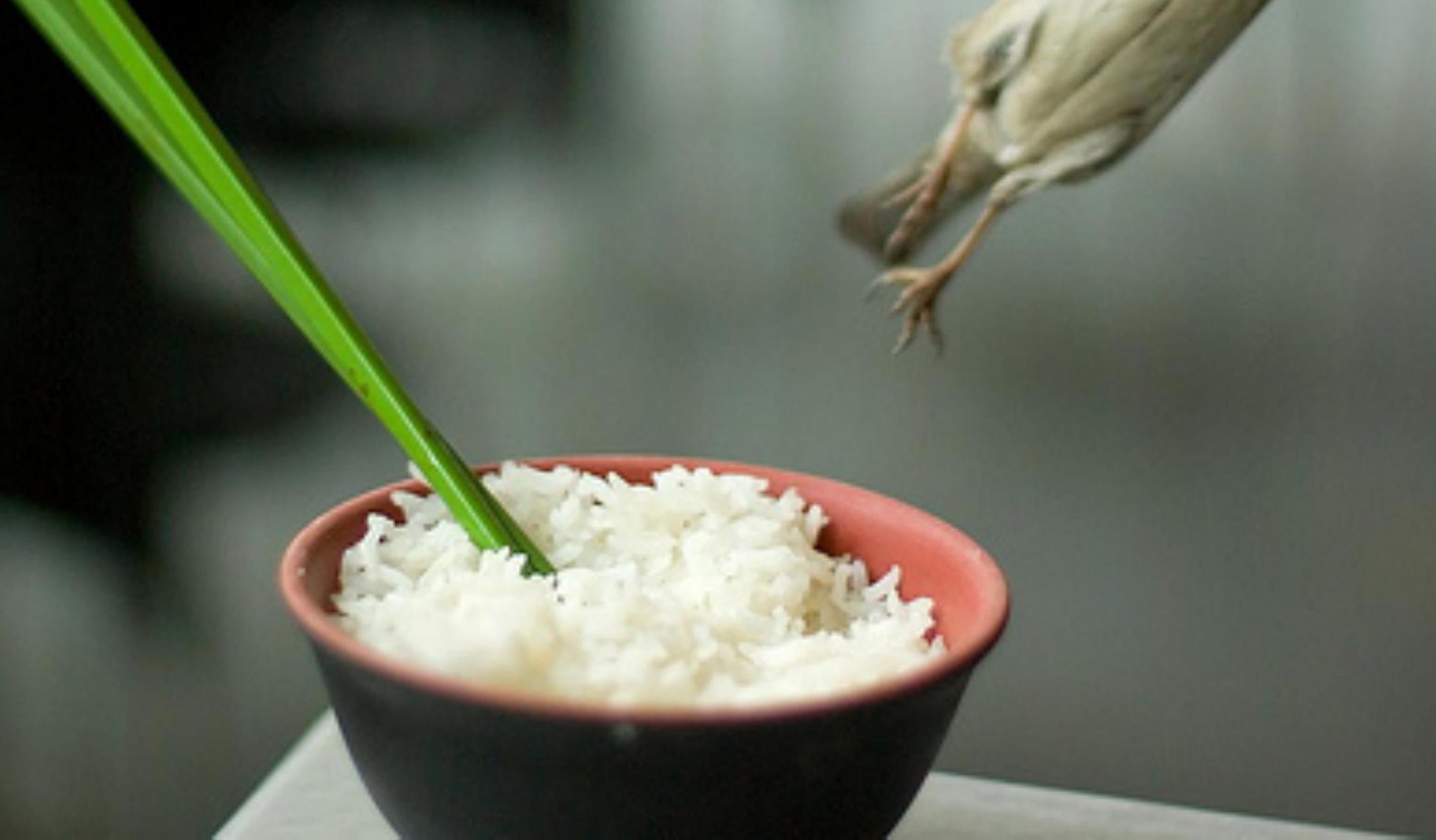


What makes mobile services successful?

- Fulfill an immediate need

- Take advantage of mobile attributes

- Easy to use

Understand how people want to use their phones 


\section{Mobile Survey - Nov. 2008}
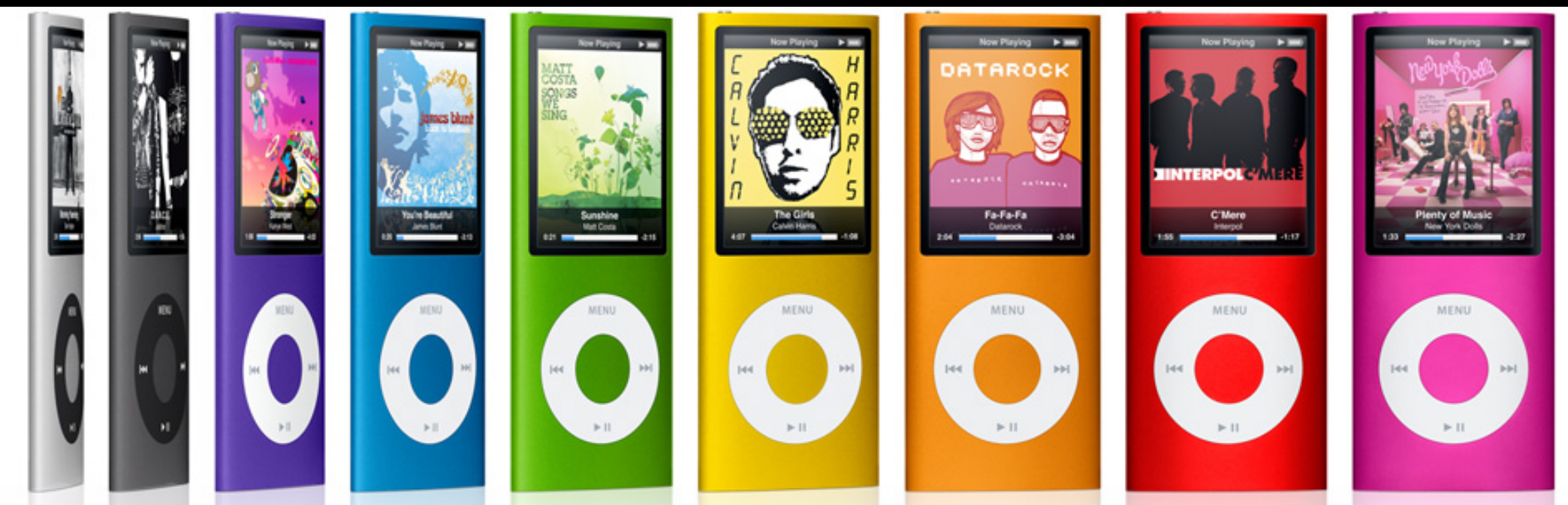

811 responses, primarily undergraduate 


\section{Cell Phone Ownership}

No Mobile Phone $3 \%$

Regular Cell Phone $76 \%$

Smart Phone $21 \%$

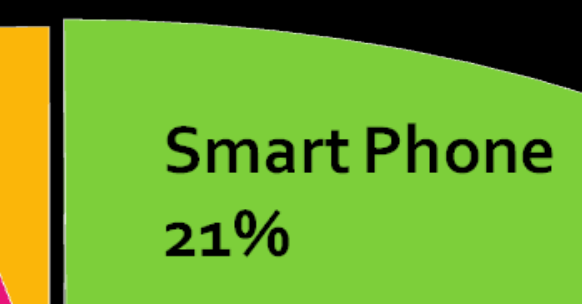




\section{Top 4 Uses}

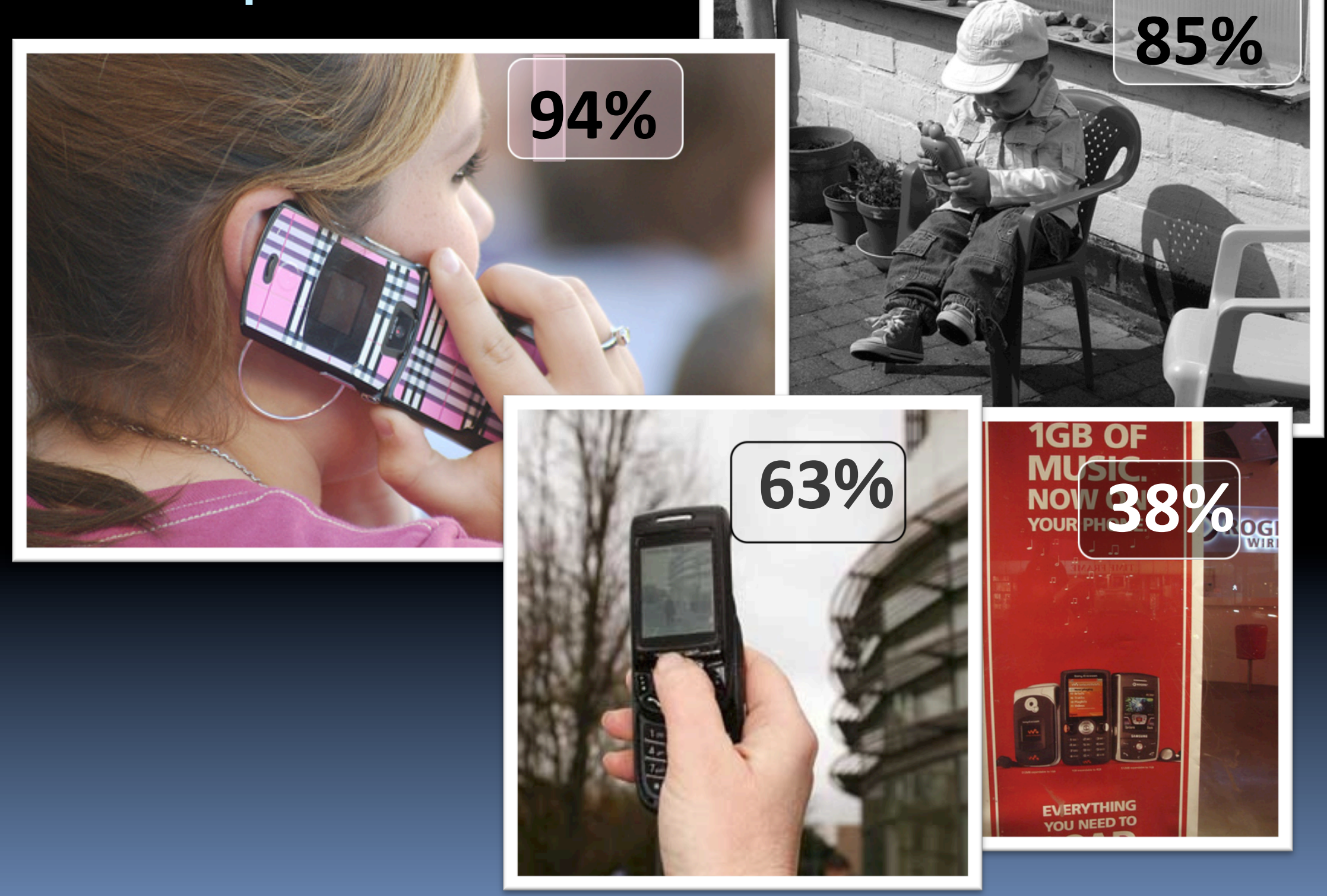




\section{Top Internet Use}

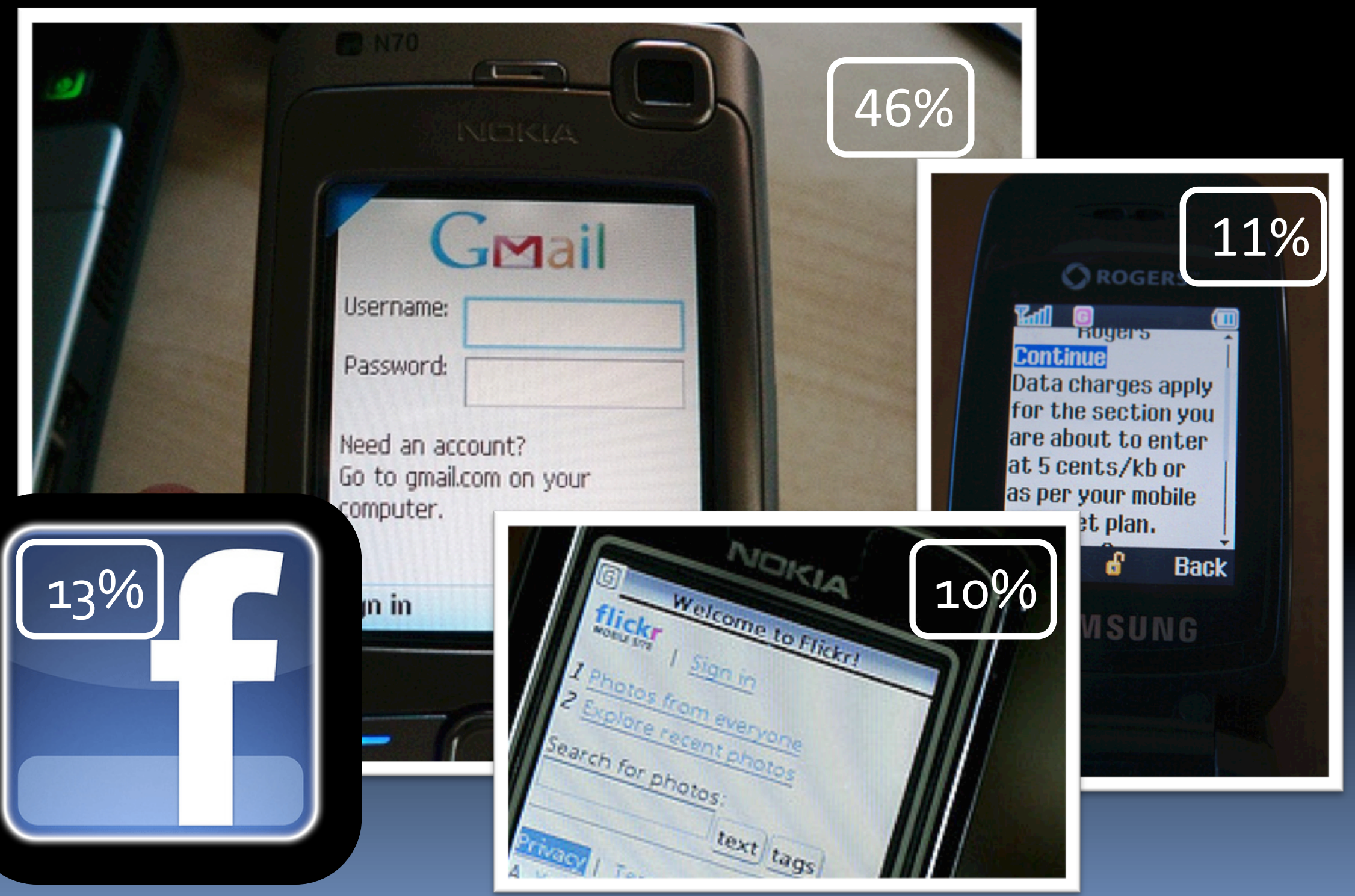


What will your next phone be?

Smart Phone $38 \%$

Undecided $37 \%$

Cell Phone $17 \%$ 


\section{Other WiFi enabled devices}

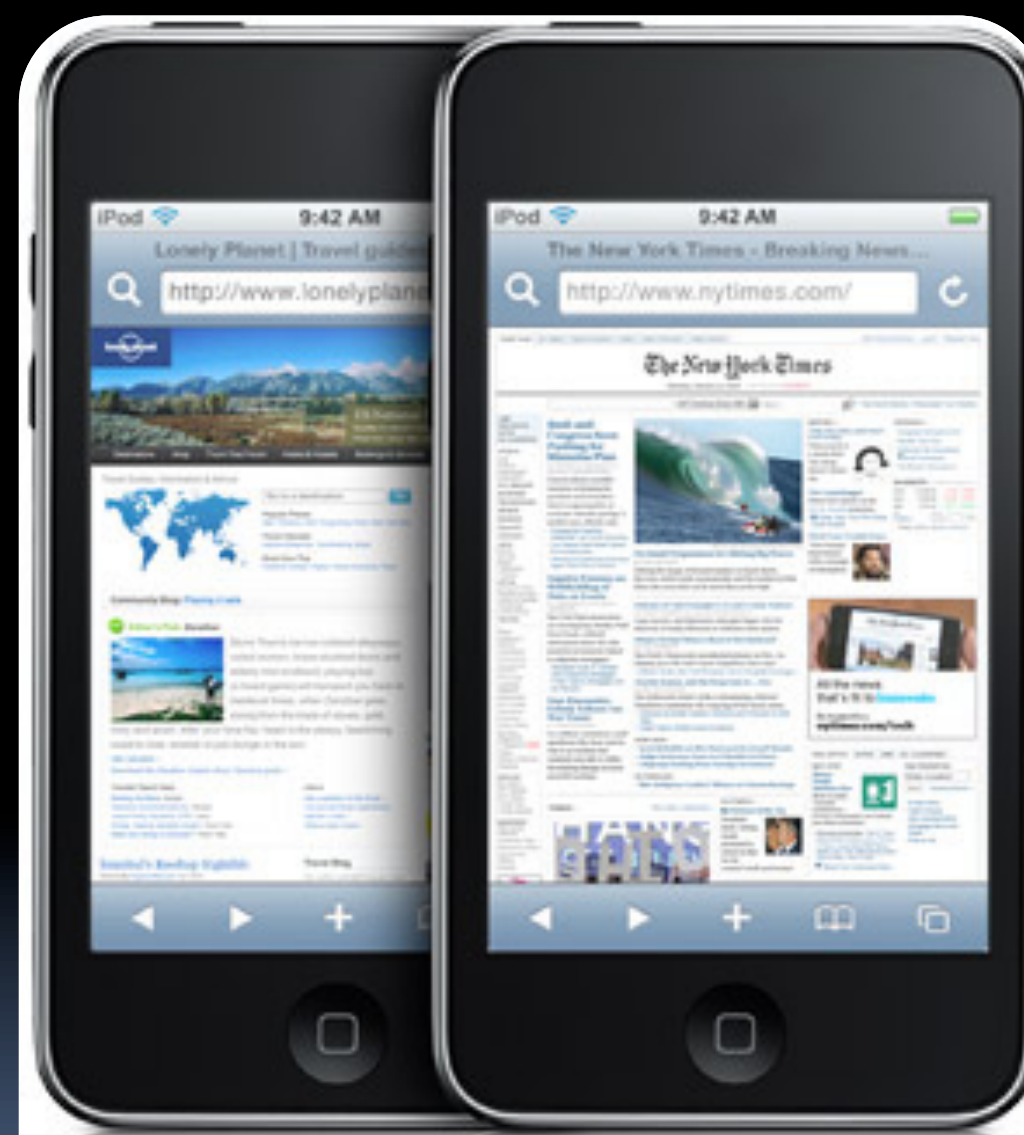

$8.7 \%$ have

$32 \%$ plan to buy 
New features wanted

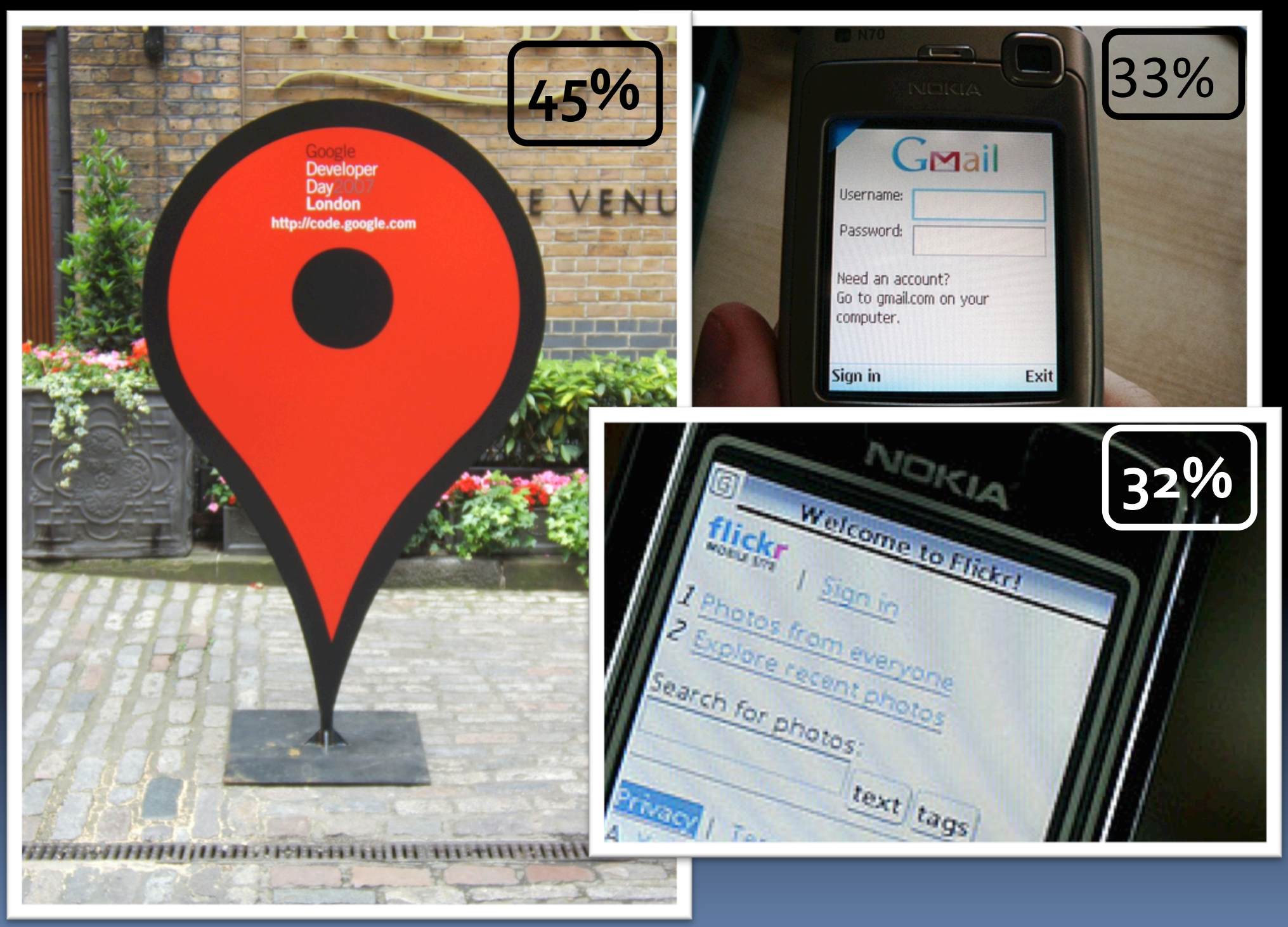




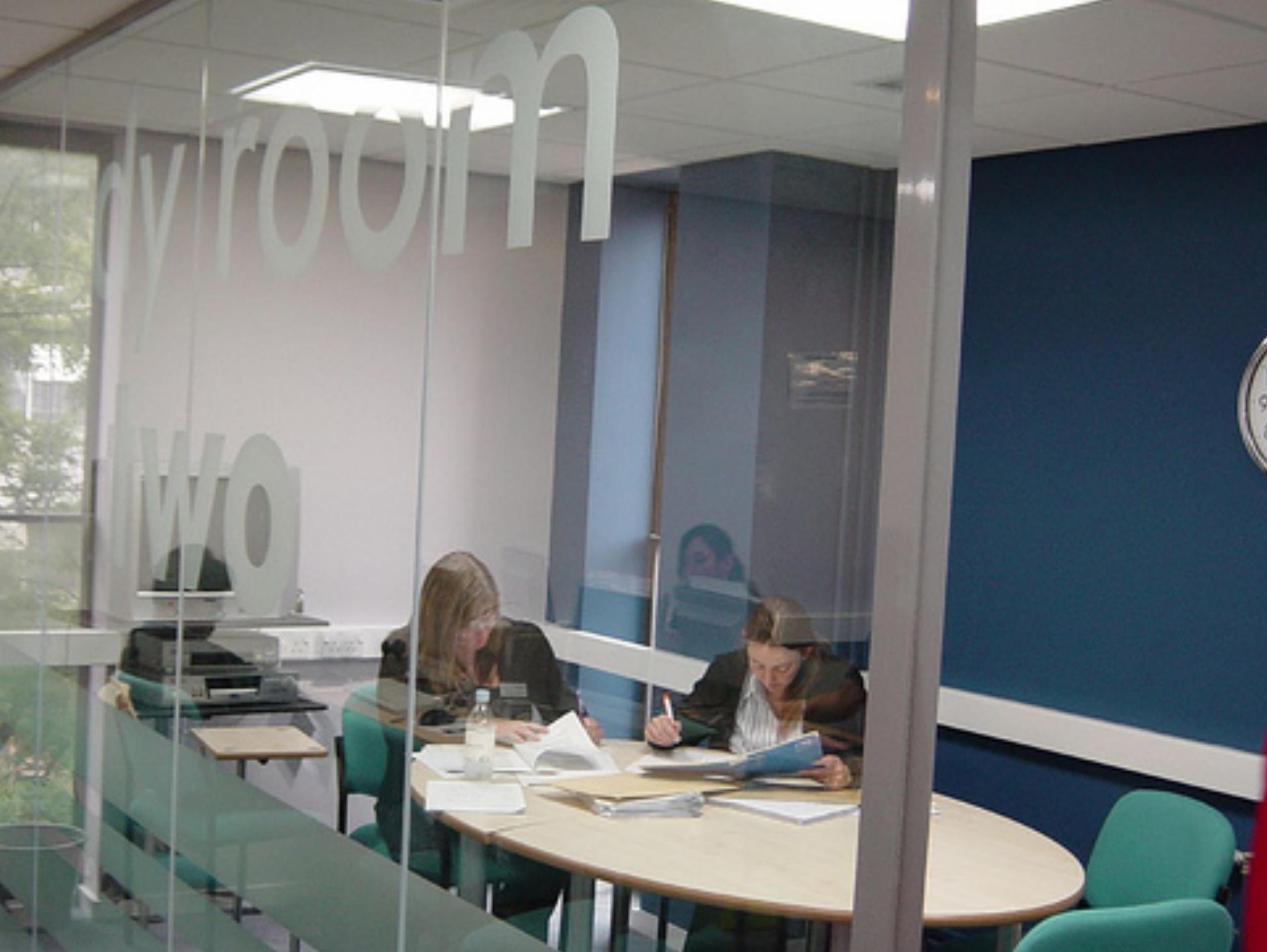




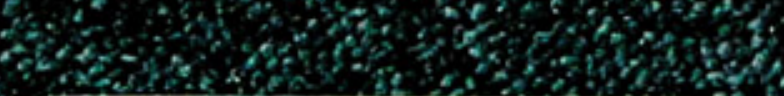

April 2008 April Avril Aprile Abril April

14 monder - Anline.

Luns

$7 \sigma^{\sin } \sqrt{-1 / 1}$

March 2000

, $3, \ldots$

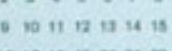

काष

कon

Aentil 2000

s $x+2+2$

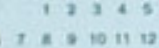

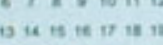

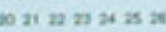

xा $2 x=x$

May 2000

Burwtos

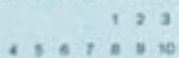

"1 1 a

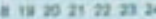

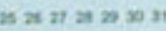

Week 16
15

Tuescor
Denstion
Nard

Mard
Moned
vares

Wartes

16 mor$$
\text { med }
$$
18:20 Ecognafáa

17 monar Acrumple menete folowa Bare woensans nisos lapele

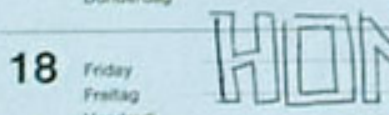

19 vernos

80

20

0 swary
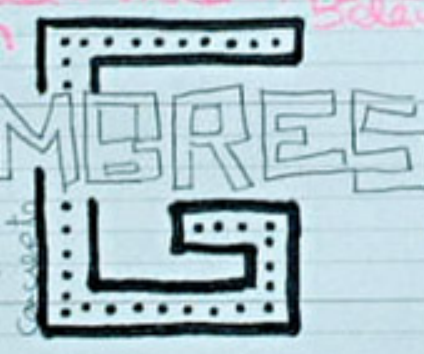

DCMTAn coleconn

\section{metiendacena} 18:00h
TRUCo!

$300>216>180$

April Abril Aprile Avril April April 2008

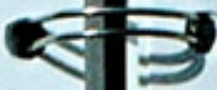

से

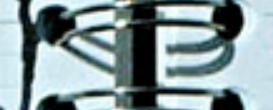

* Cumple de Rocío

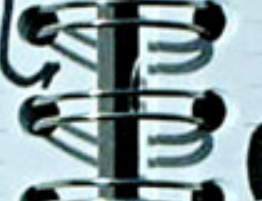

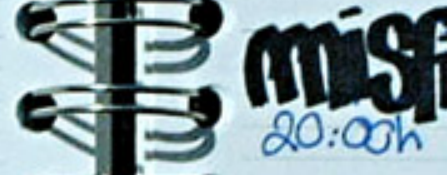

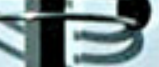

Nade de lo libstess

CIERRE MC

MTETS

24

स्ञ

]

स्षि

Exposive de Plesen Sift

स्ञाछ

स्ञा巳

Cut

Georeatan

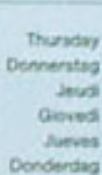

Donderdag

mater

25

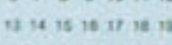

सम

5

$\cos +2+2$

\&

ane Last wod D_L_L:

Concierto:

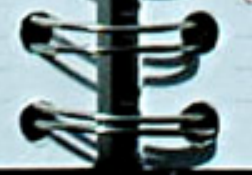

我

Week 17 

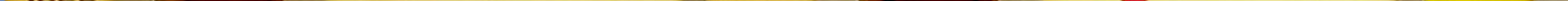


\section{XVIR}
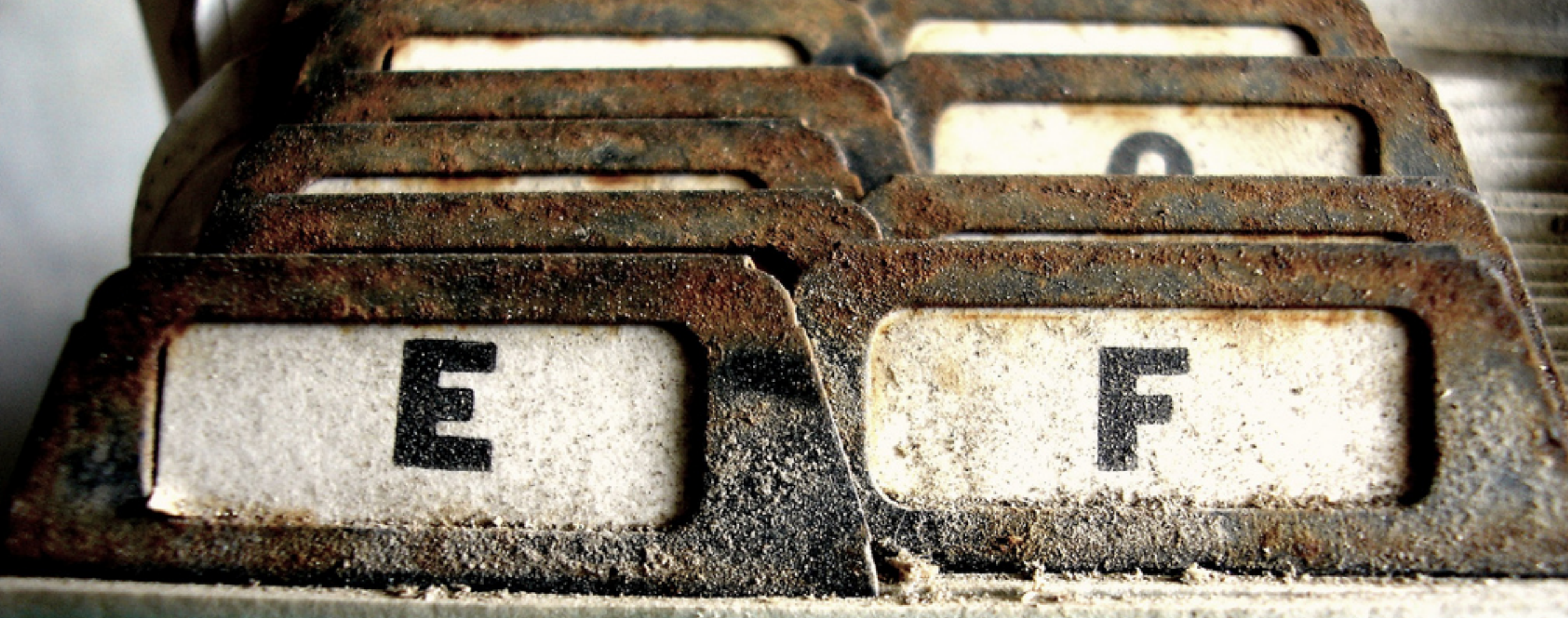


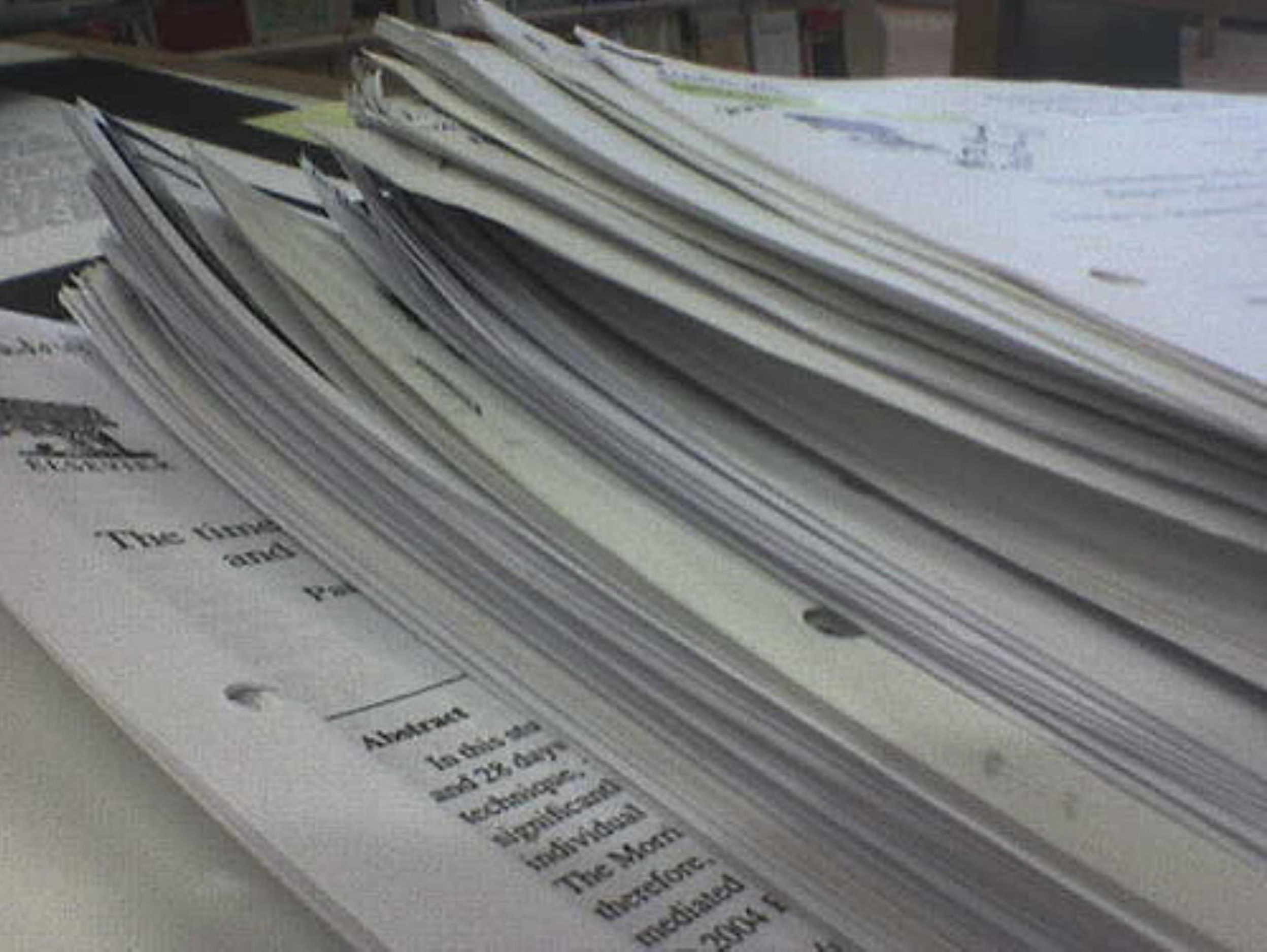




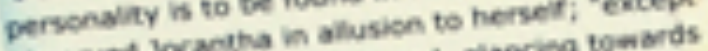

observed locantha in alusich to helancing towbrds

pertaps Atrab," the controt that lay in

the large tably-marked cat that lay in dran. Ate

the targe table ease in a corner of the dran wing

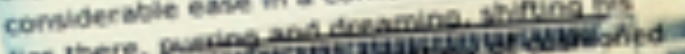

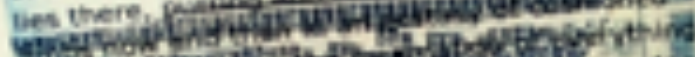

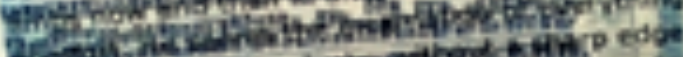

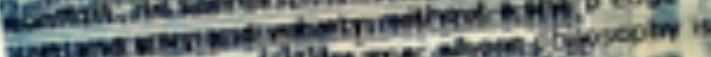

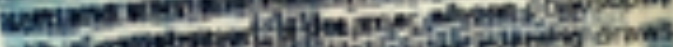

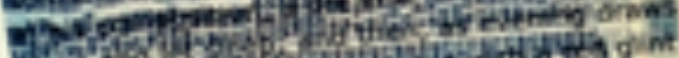

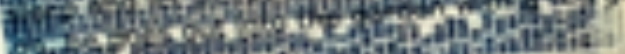

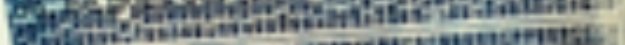

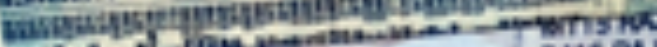

B4t6 PN

ACH 230 . cen

RU ivan ... I18h

Nis eves and slays a drowny sparrop the 2962 i... I49

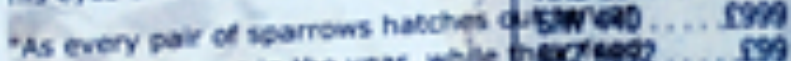

more young ones in the rear, while frogteses. . . . .99

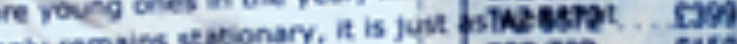

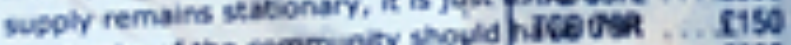

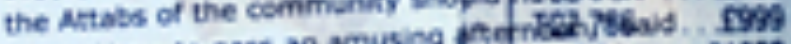

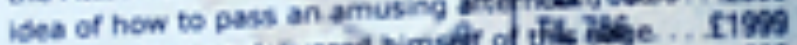

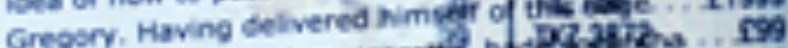

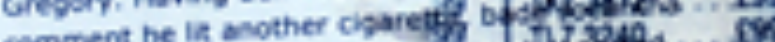
cemment he in another cigare the ber a plaveully atiectionate inestas

- valuaht, astips

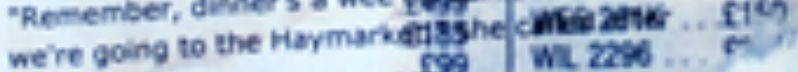
were
him.

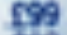

\section{9}

WL 1309

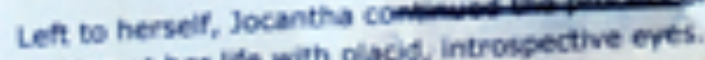
looking at her lide with placidy introbsective ext: If she pad pot ererythiag ghe wanted in this world, at kast she was vey well pleased weth for

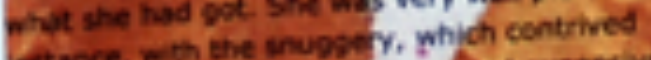

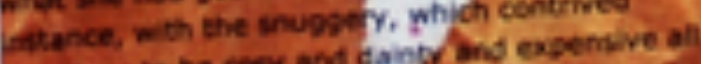
somehow to be coor and canty and exporinte on

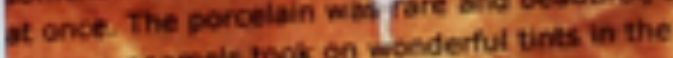
Chinese cramels took on monderfut thas Le the

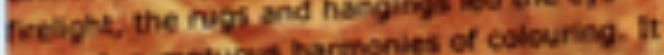
through s.mptuous harmonies of culserisg. was a roem in which one might have misthy but entertaincd an ambase

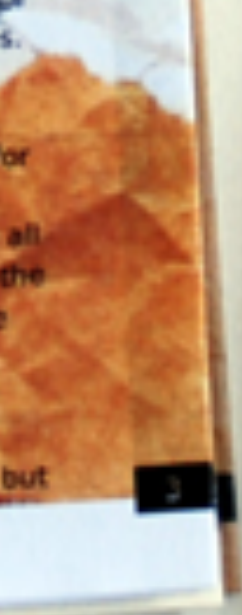

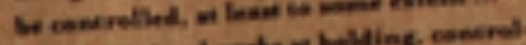




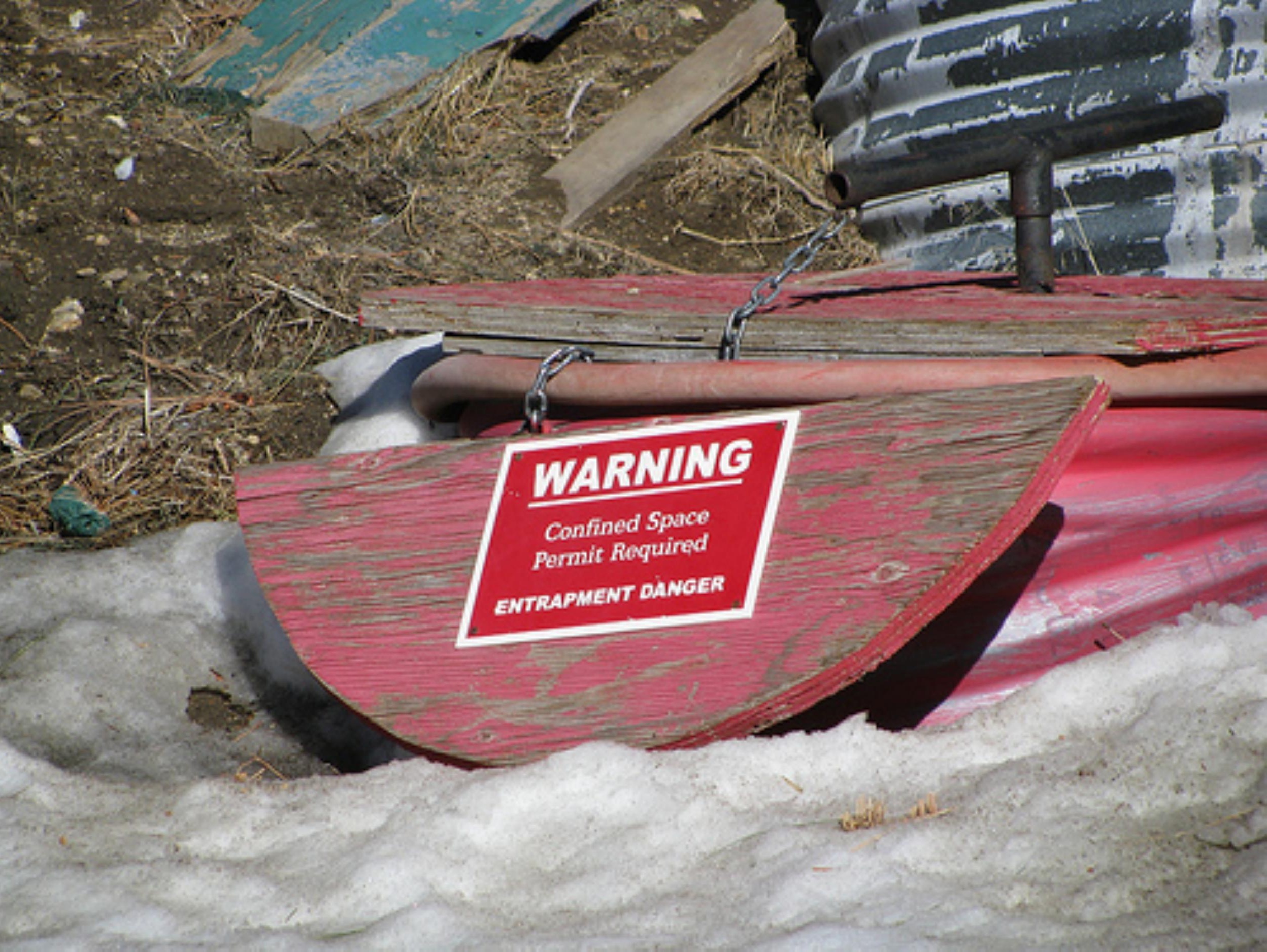




\section{Texting from Catalogue}

\section{Send SMS Message}

Title: The ghost map : the story of London's

Call \#: RC133.G6 J64 2006

Floor
Location: 10 th

Select Service

Provider:

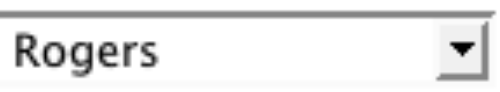

Cell Phone \#: eg. 416123

NOTE: carrier charges may apply

Go Back

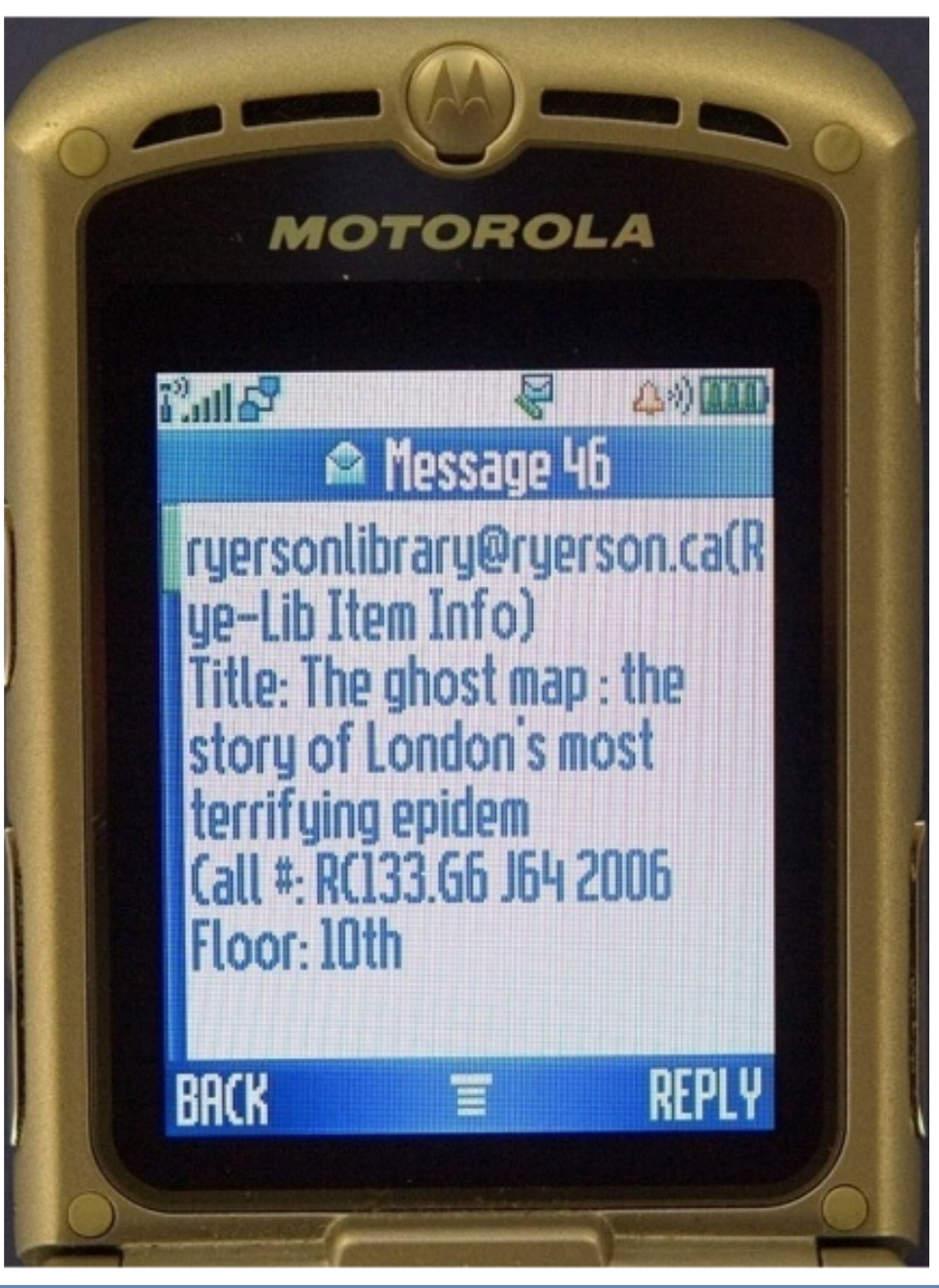




\section{Study Room Booking}

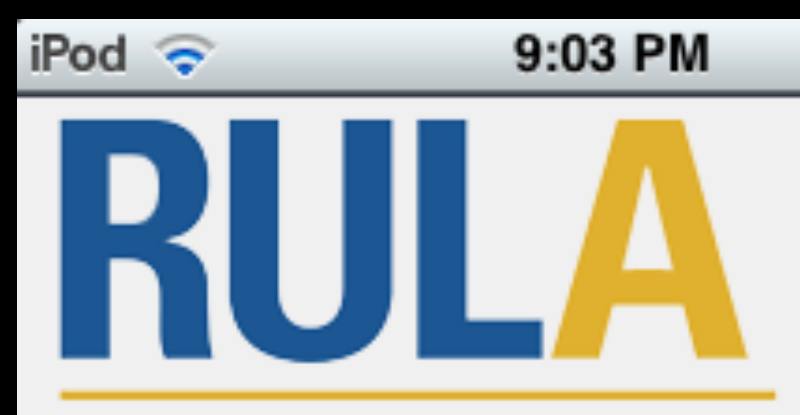

Ryerson University Library \& Archives

\section{STUDY ROOMS}

Menu:

Search Bookings

Book A Study Room

View Room Availability (Within the next 4 hours)

View Booking Policy

$>$ 


\section{Mobile Catalogue}

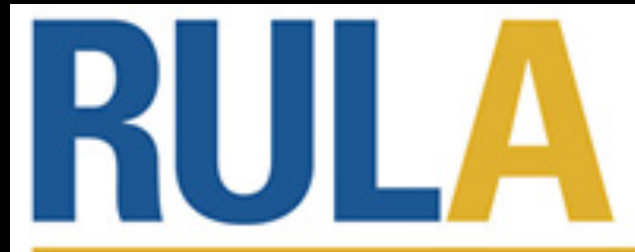

Ryerson University Library \& Archives

Welcome to Ryerson's mobile library catalogue

AUTHOR $\sqrt{ }$

Search

Advanced Searching

View your patron information

Need help searching?

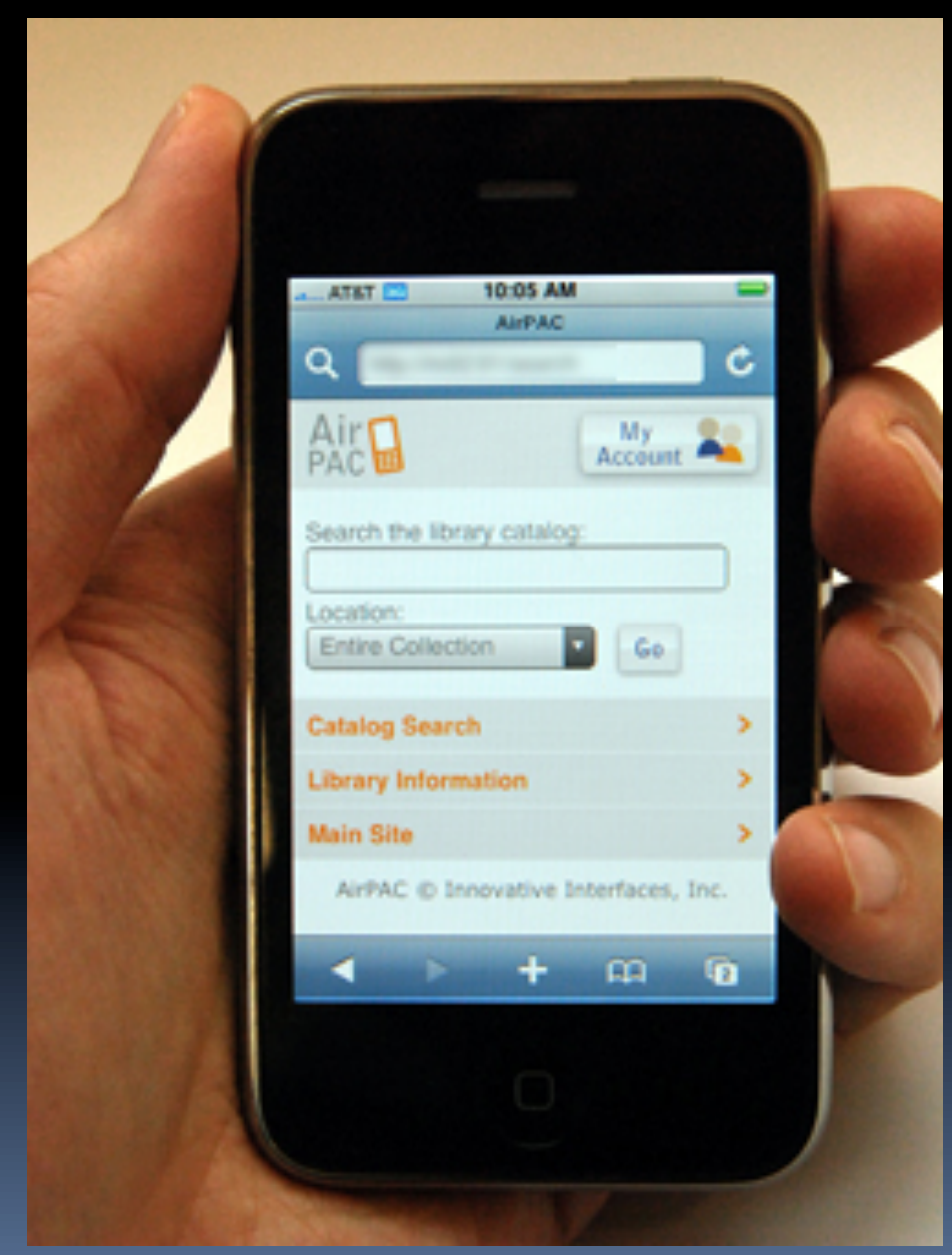




iPod $₹ \quad 9: 01 \mathrm{AM}$

\section{Find a \\ Desktop \\ Computer}

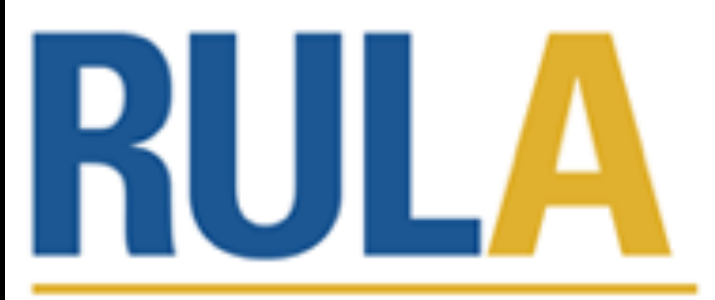

Ryerson University Library \& Archives

\section{Lab Computer Availability}

\section{2nd Floor}

35 / 43 available

2nd Floor - Information Learning Commons Lab

66 / 87 available

2nd Floor - Information Commons

$1 / 2$ available

2nd Floor - Learning Commons Scanners

7 / 16 available

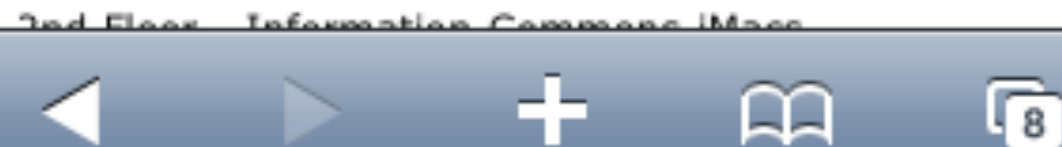




\section{Find a \\ Laptop}

Ryerson Library Laptops

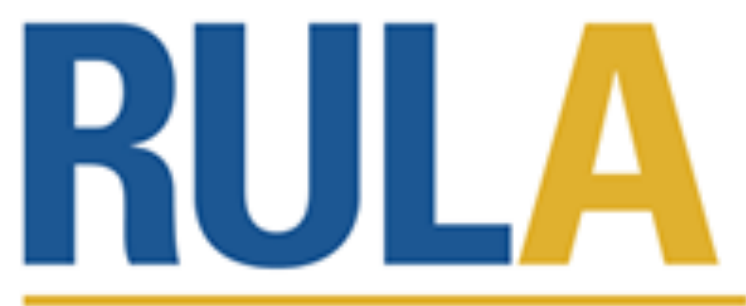

Ryerson University Library \& Archives

\section{Available Laptops}

There are currently $\underline{67}$ laptops available.

For more information about our Laptops see:

Laptop Loan FAQ Laptop Lending Policy Laptop Loan Agreement Form

$>$ क क $\sqrt{8}$ 
Login Screen

Campus Assistant

Log in

my.ryerson:

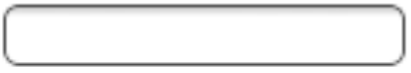

password:

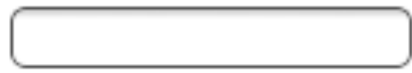

$\log$ in 
Main Menu 
Main Menu Alternate Colour Scheme
iPod $\approx$

3:08 PM

$\square$

Ryerson

Campus Assistant

Welcome, Graham McCarthy!

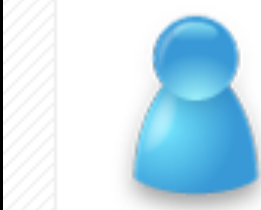

Profile

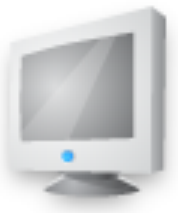

Find a Computer

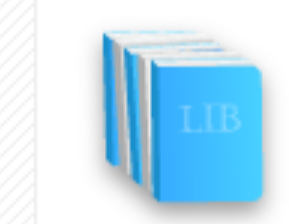

Library
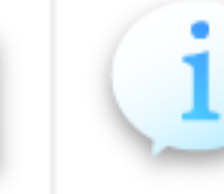

About

Directory

News

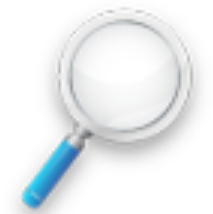

Map

Book a Room

$\mathrm{AaBbCc}$

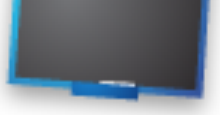

Book a Room
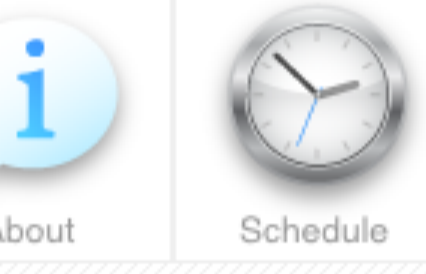

$>$

$-$

कि

$\sqrt{2}$ 


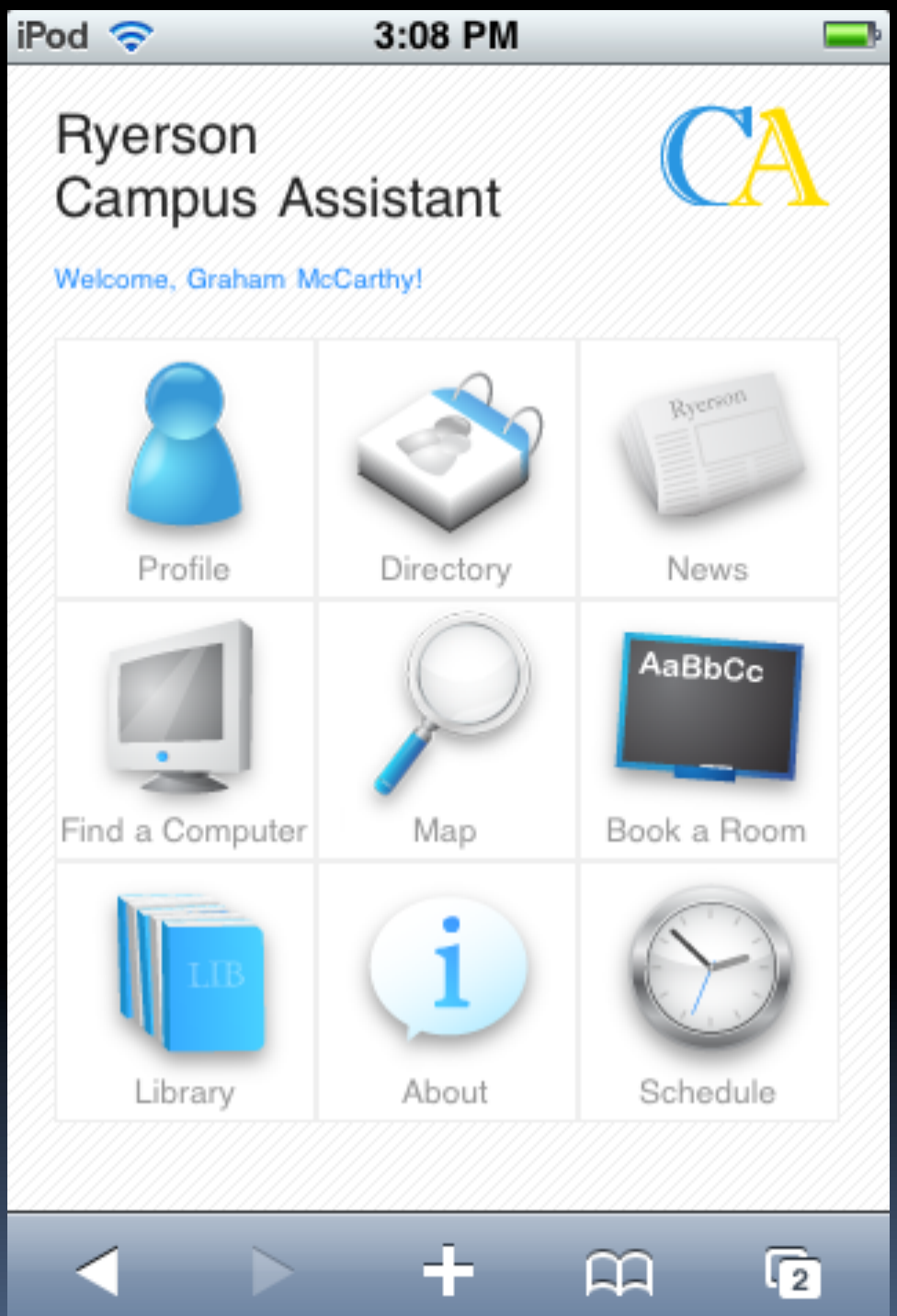

Profile App 


\section{Profile App}

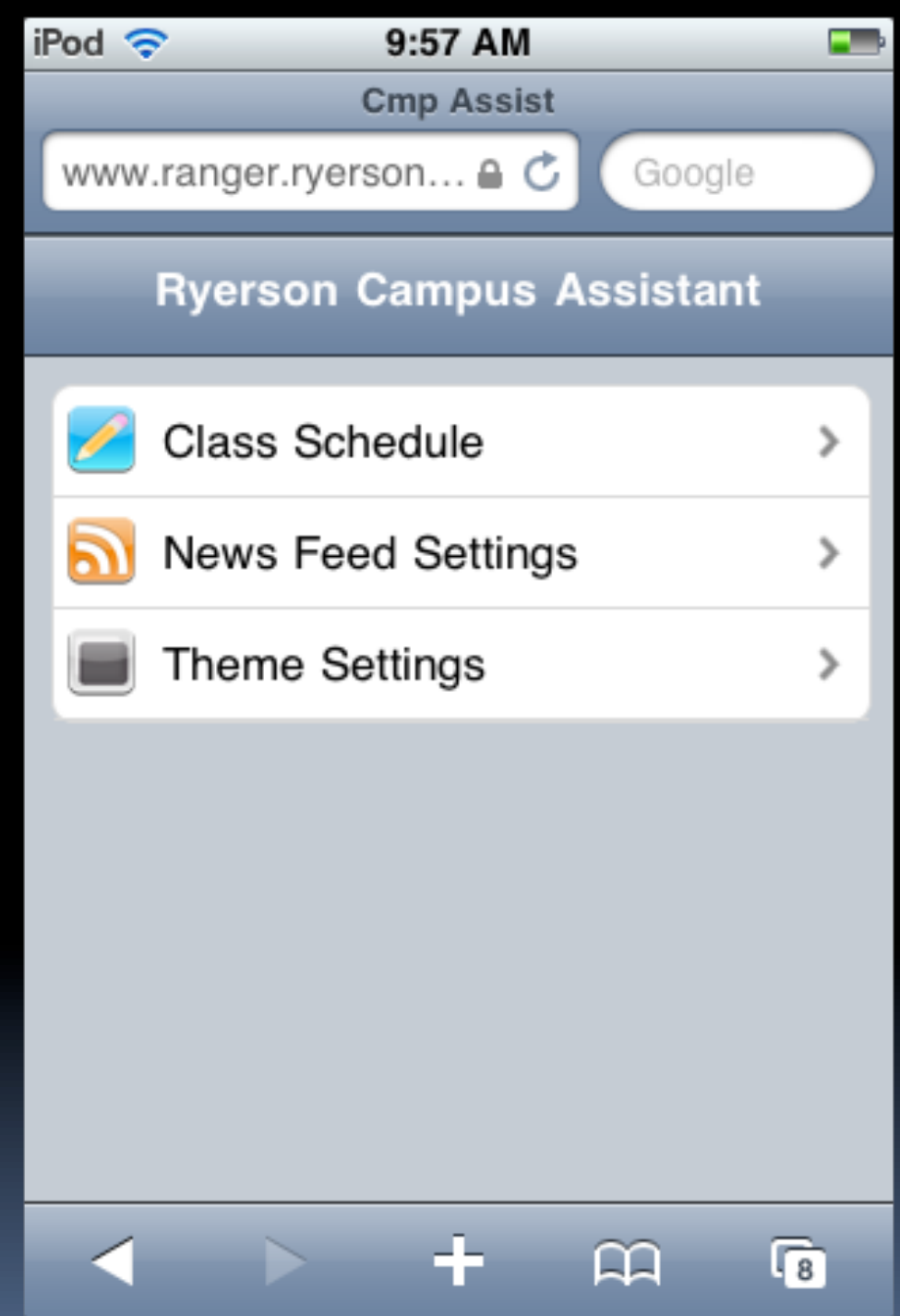


Ryerson Campus Assistant

\section{Profile App}

Subscribe to News Feeds
Adam Carlucci's Profile

News feeds

Title

Show Items

RU News

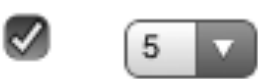

RU Research News

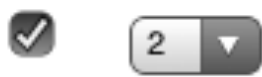

RU Campus Events

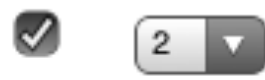

Save Settings

\section{Preferences}

+ 㞋 而




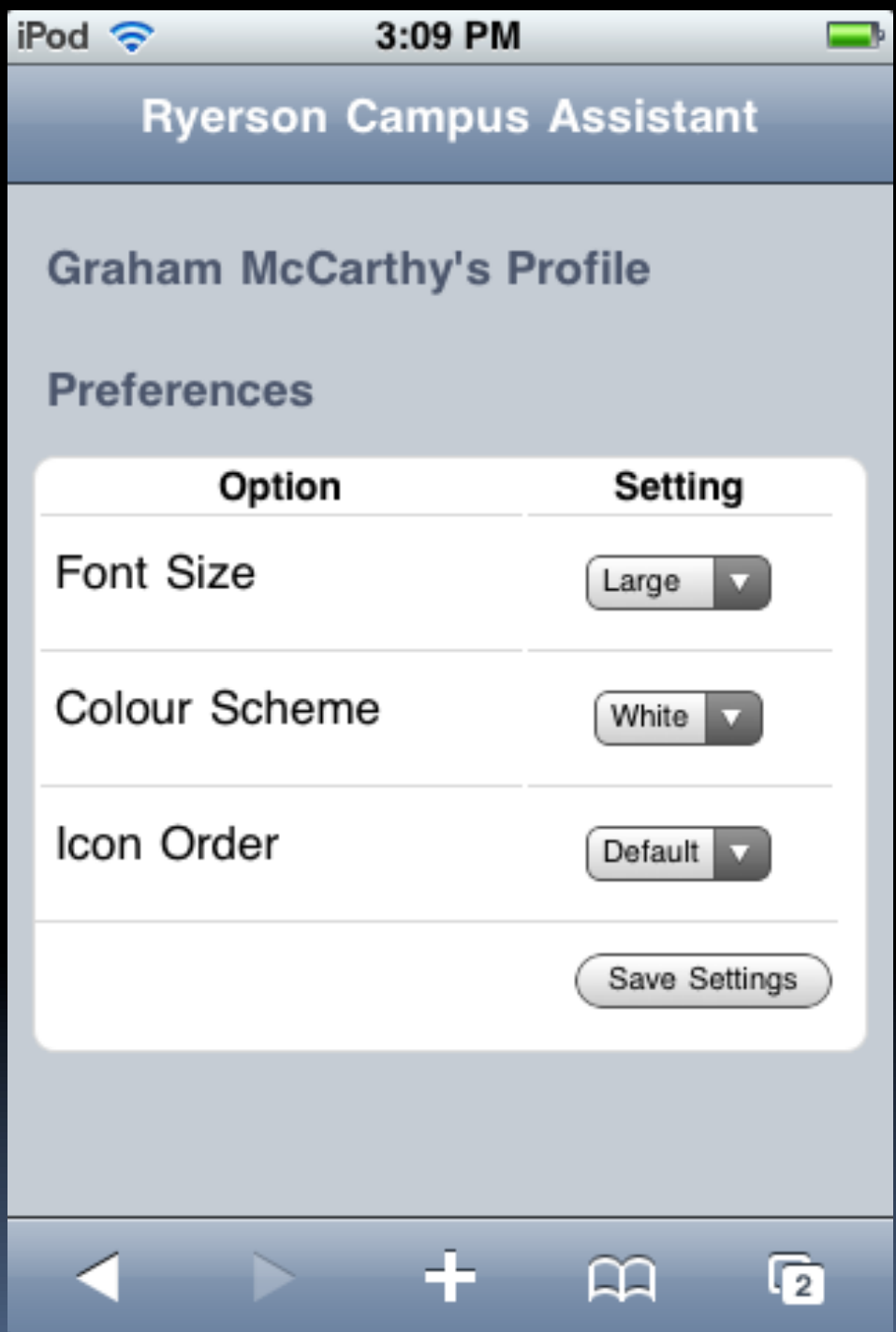

\section{Profile App}

Manage Preferences

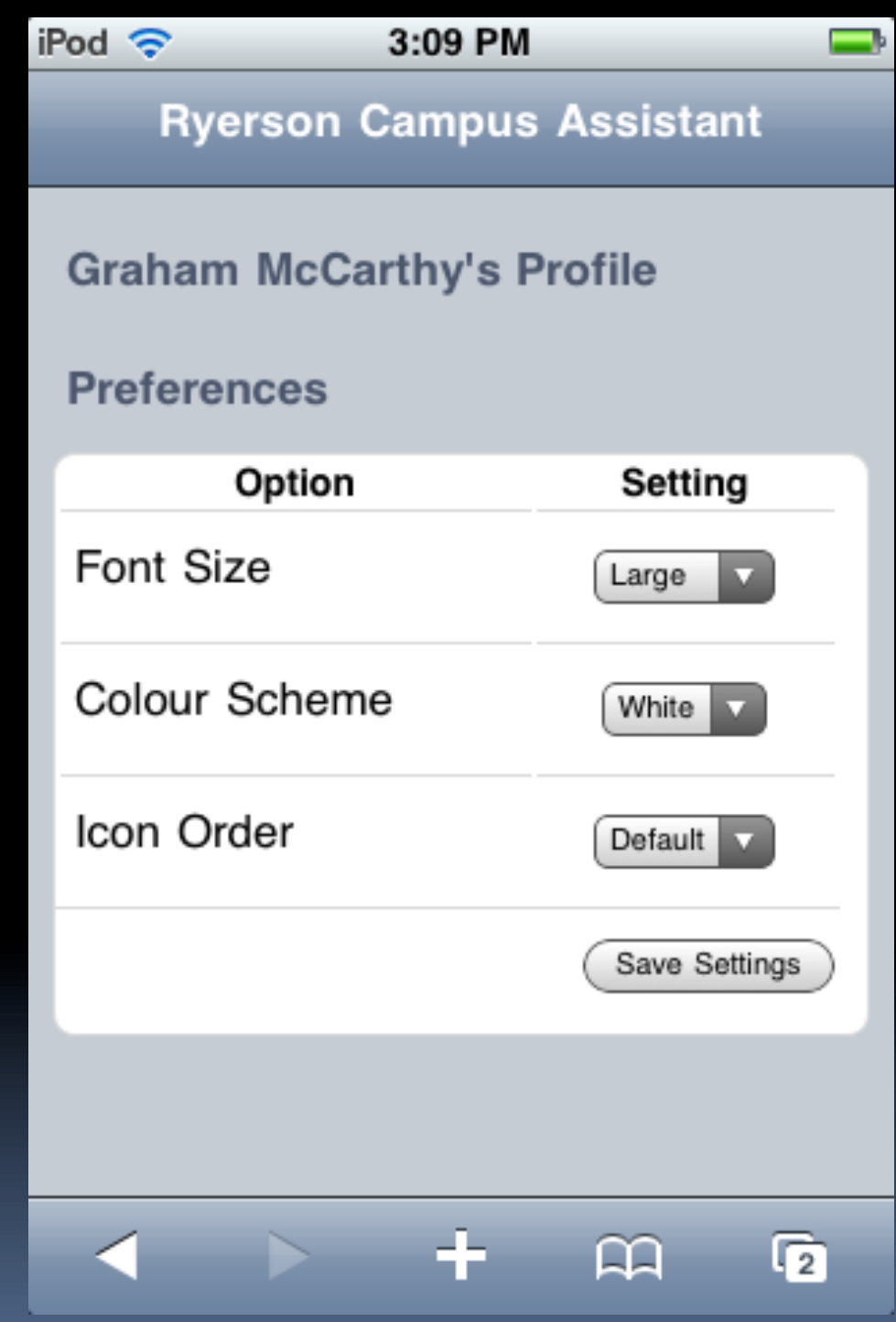




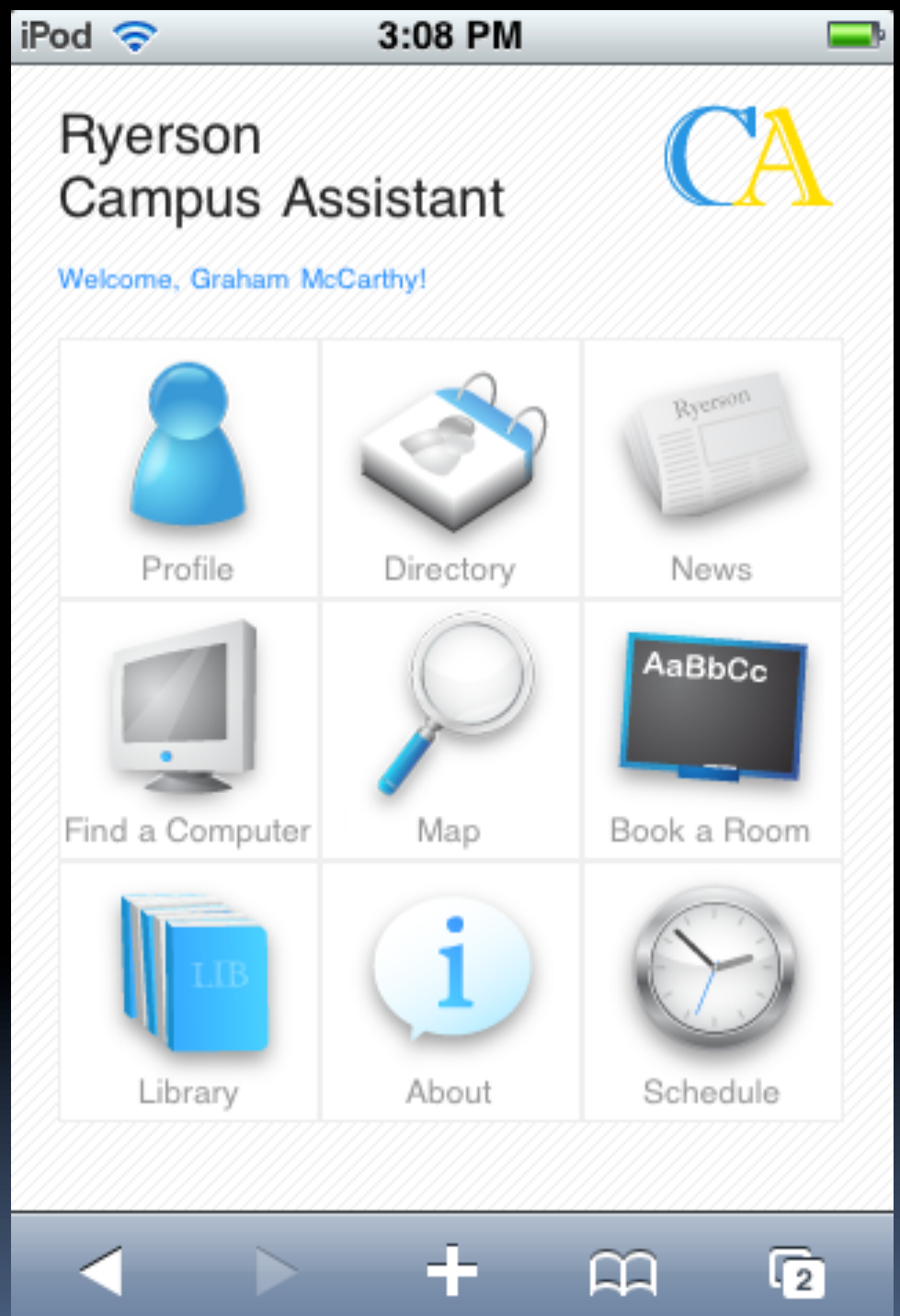


iPod $\approx$

\section{Directory}

\section{Directory App}

Search By Name

First name:

Last name:

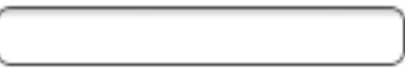

Find

Search By Department

$\nabla$

Find

$\checkmark>+$ A $\sqrt{2}$ 
iPod $\approx$

Directory

\section{Directory App} Searching by Name

\section{3:08 PM}

$\square$
Create a new search

Search result for G Mcca:

\section{McCARTHY, Graham}

Programmer I

Location: LIB-667

Extension: 2119

Email: gmccarthy@ryerson.ca

$\triangle>+$ 飠 $\sqrt{2}$ 
News and Events App

\section{Ryerson}

Campus Assistant

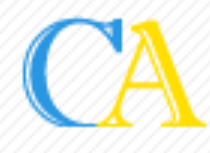

Welcome, Graham McCarthy!

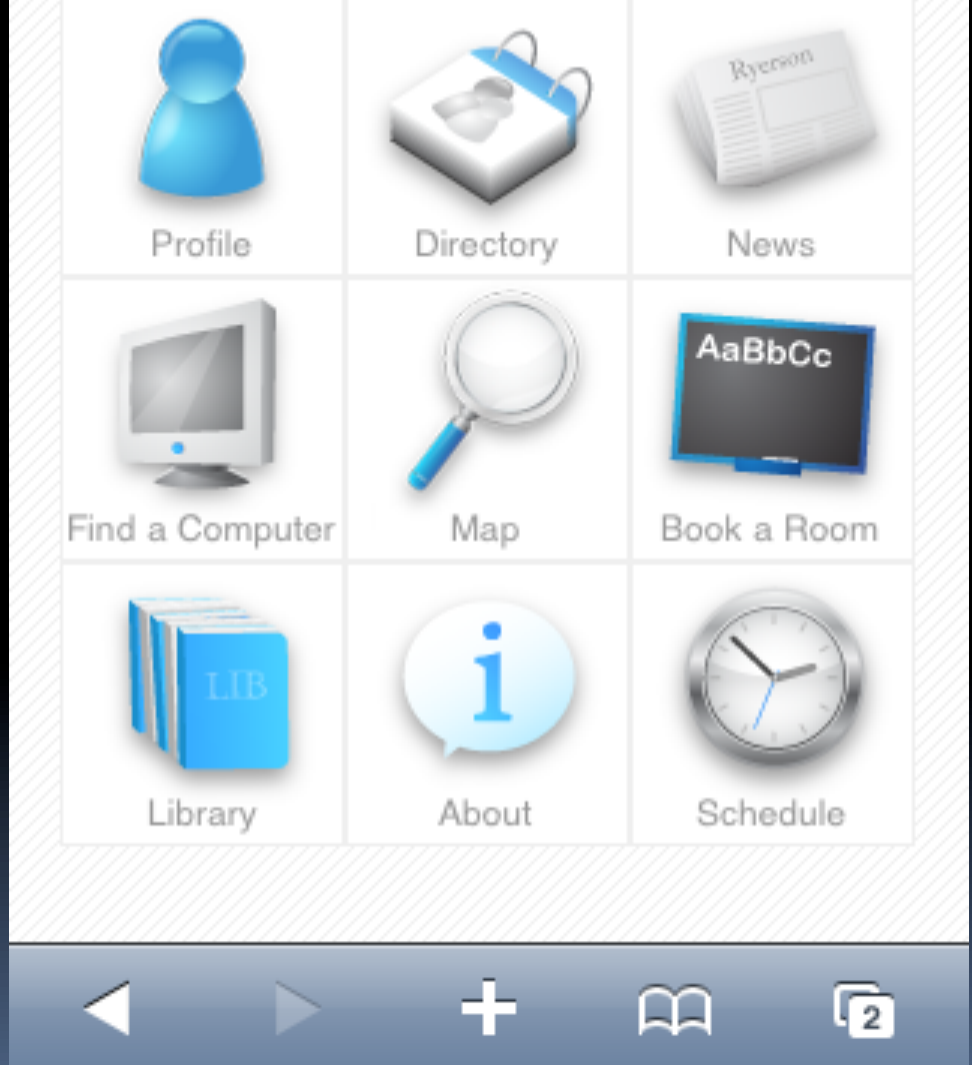


www.ranger.ryerson... ค C

\section{Google}

News and Events App News Reader

\section{Ryerson University News}

Convocation: A time to celebrate student success

Jun 08,2009

4,766 students eligible to graduate at spring ceremonies

Ryerson coach Richard Dean leading semi-pro female basketball team

Jun 05,2009

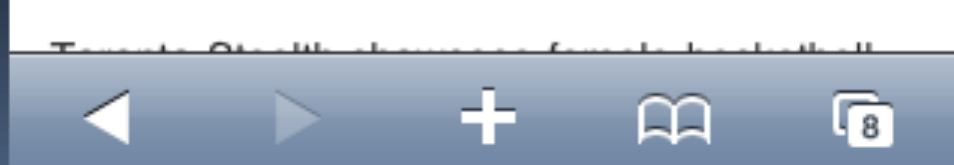


Find a Computer App

\section{Ryerson}

Campus Assistant

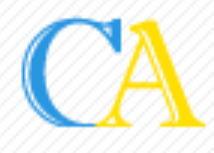

Welcome, Graham McCarthy!

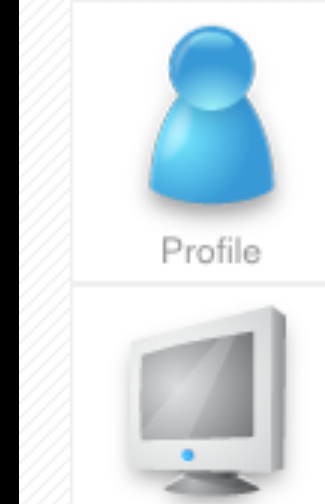

Find a Computer

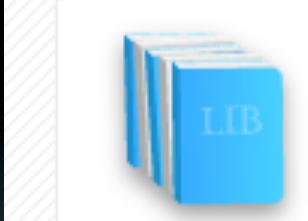

Library
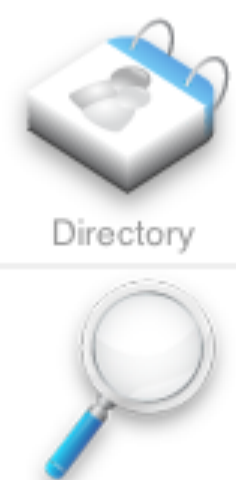

Map

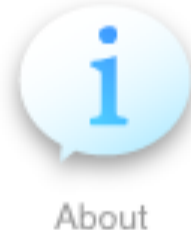

About

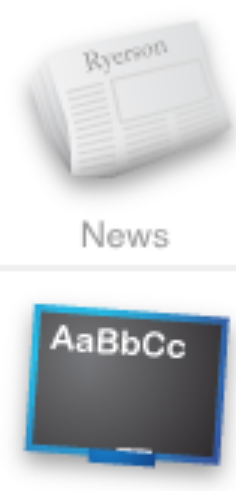

Book a Room

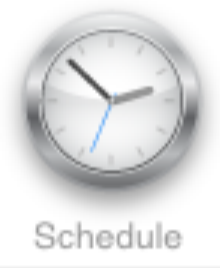

$$
<>+\sqrt{2}
$$




\section{iPod ₹ 3:10 PM \\ Find a Computer}

\section{Find a Computer App}

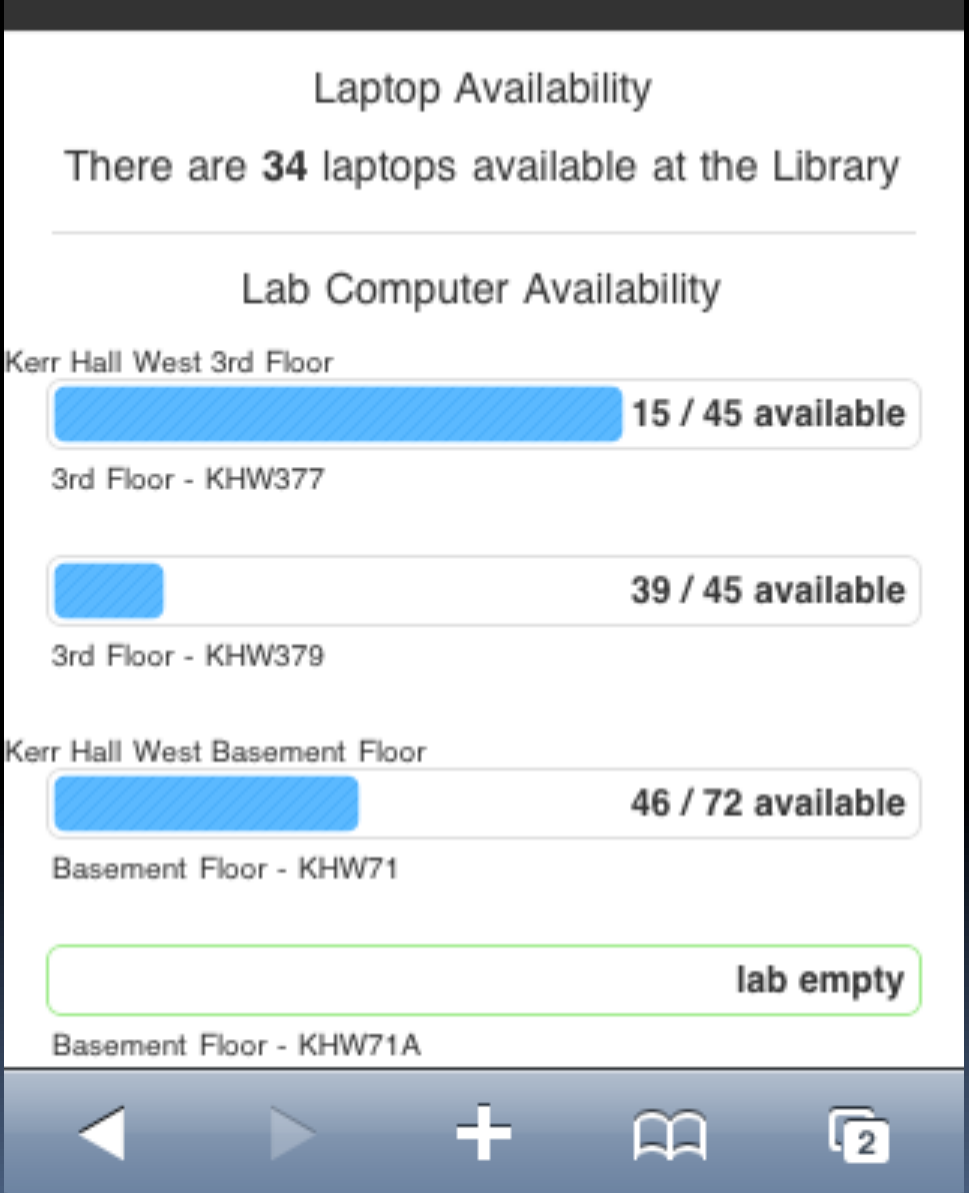


iPod $\%$

Ryerson

Campus Assistant

Book a Room App

Welcome, Graham McCarthy!
3:08 PM

$\square$

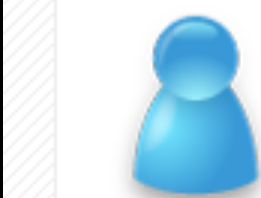

Profile

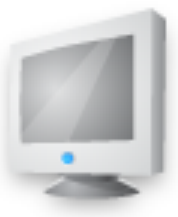

Find a Computer

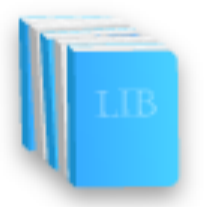

Library

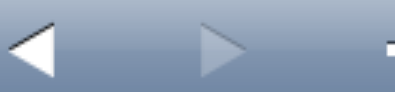

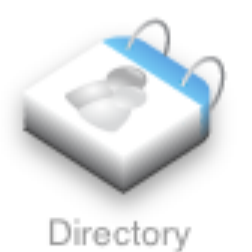

News

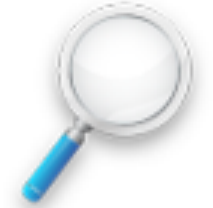

Map

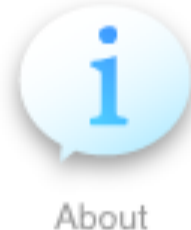

About
Schedule

$\mathrm{AaBbCc}$

Book a Room

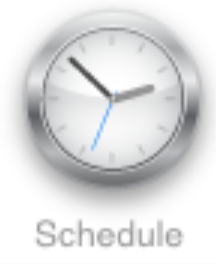

+ 瓜 $\sqrt{2}$ 


\section{Book a Room App}

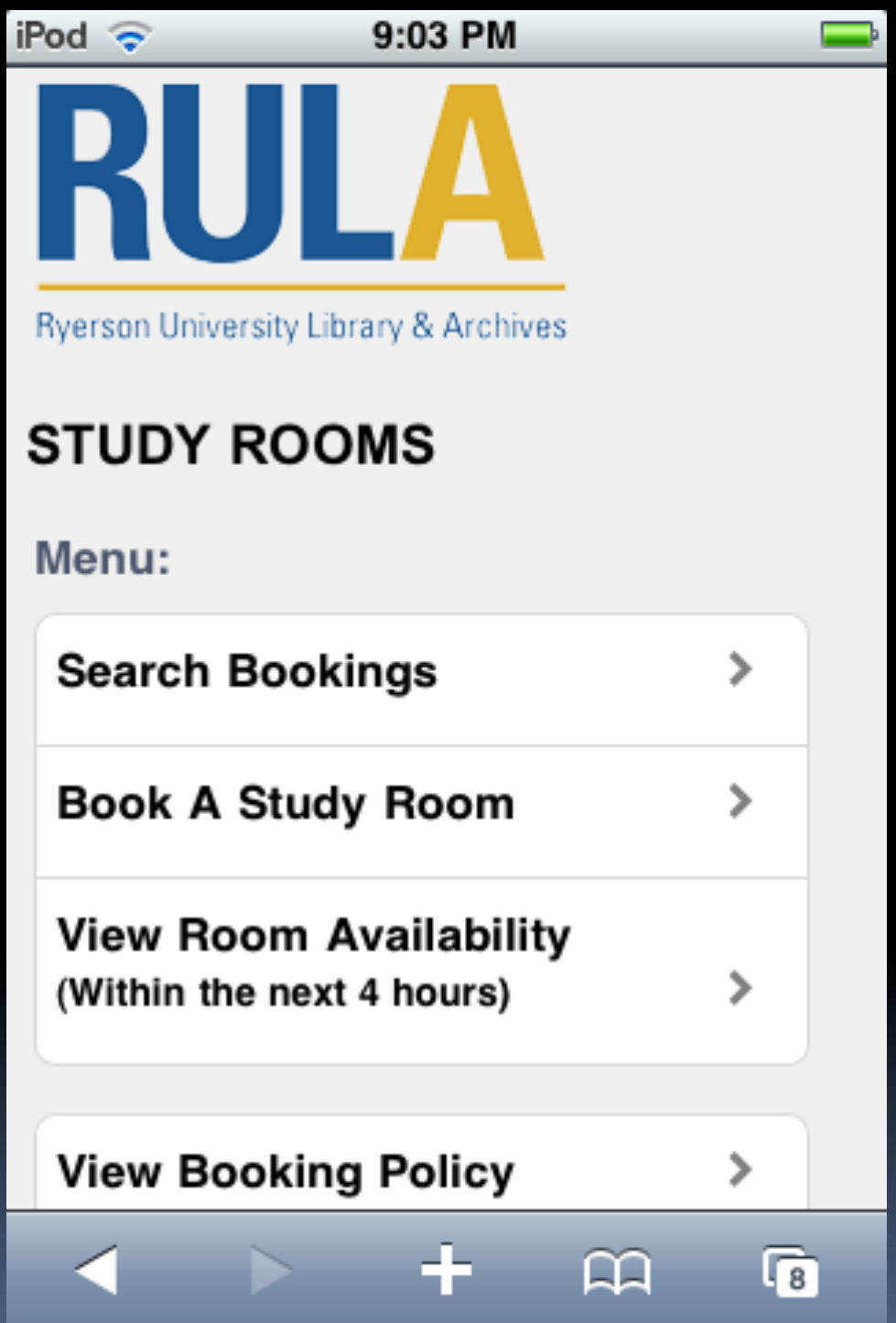




\section{In the works}

\section{iPod $\curvearrowright$ 3:08 PM \\ Ryerson \\ Campus Assistant}

Welcome, Graham McCarthy!

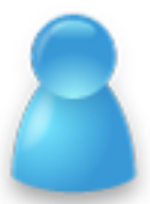

Profile

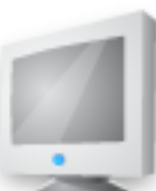

Find a Computer

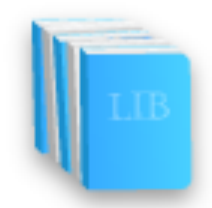

Library

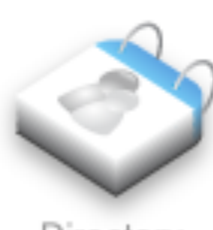

Directory

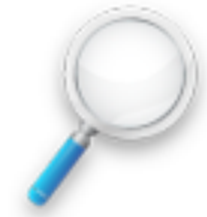

Map

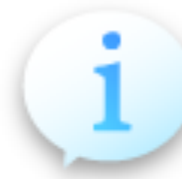

About
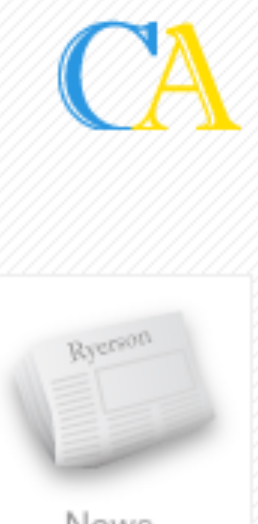

News

$\mathrm{AaBbCc}$

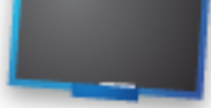

Book a Room

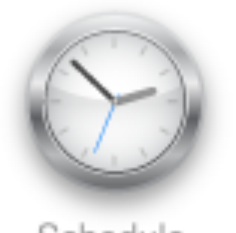

Schedule
- Library Resources

- Mobile Catalogue (available on Library website)

- Patron Record (available on Library website)

- Research Guides

- Relevant Information based on faculty and courses enrolled in

- Mapping Function

$\square$ Find buildings, offices, labs, facilities, services, etc...

- Student contributed Apps 


\section{Location Based and Context Aware Services}

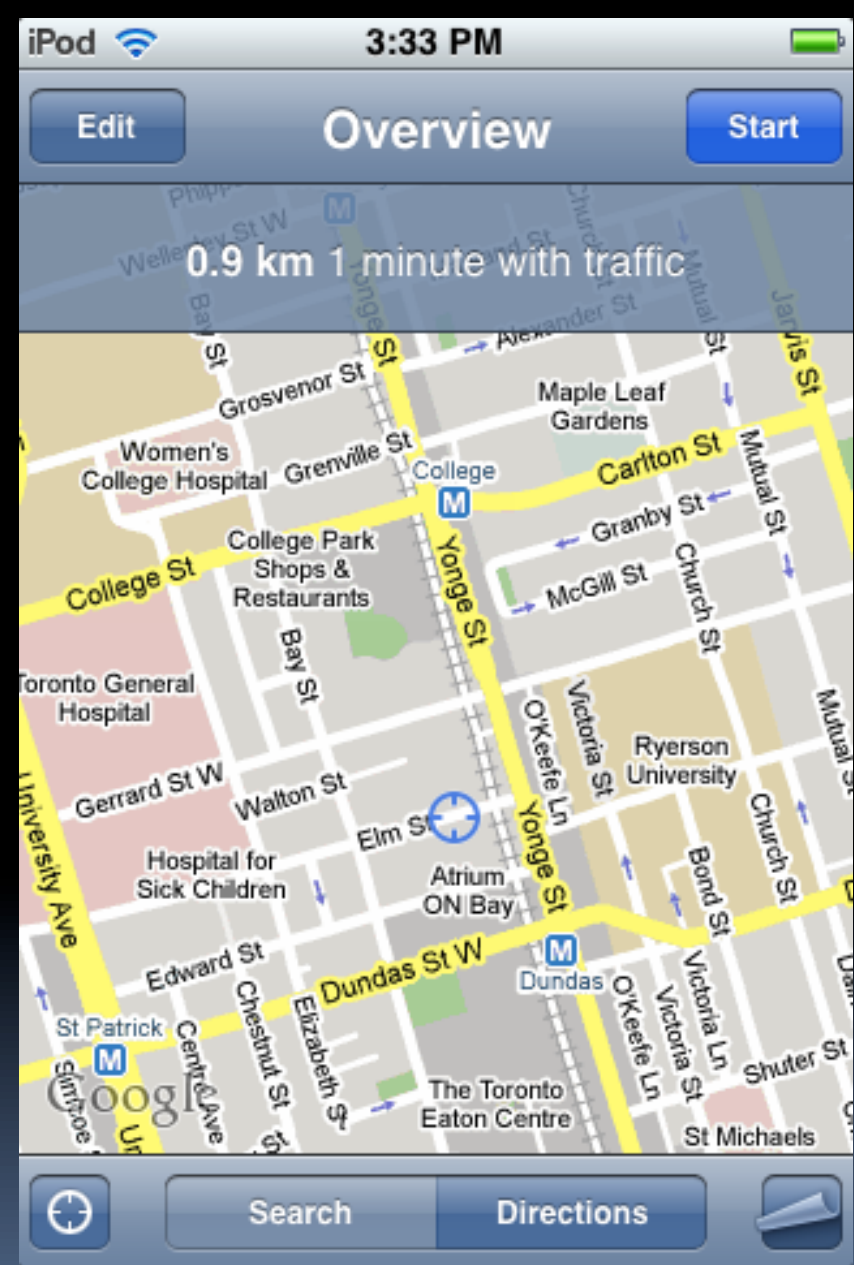

- Computer Science

- Hossein Rahnama, phD candidate

- Delivers relevant information based on student's location and profile information

- Uses GPS and Wi-Fi positioning technologies

- Specific to iPhone, iPod Touch, Google Android 


\section{Benefits to the Library}

cel $=0.08 \%$

- Active participation in design and development

- Providing innovative services to the campus community (not just books and e-journal access...)

- Primary focus on student success

1- Fostering collaboration with faculties and departments

- Seen as a neutral ground for launching new services

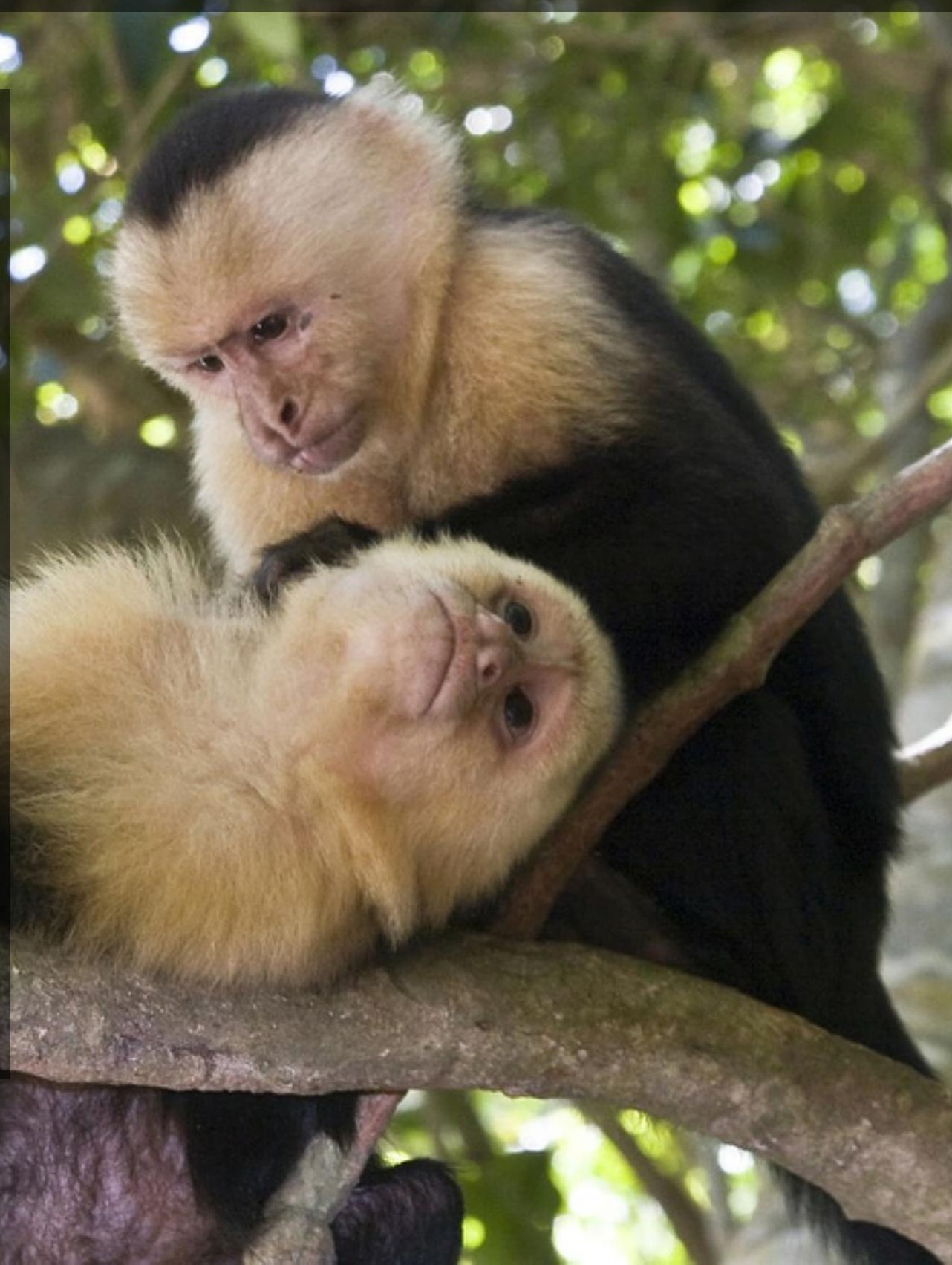




\title{
Thank you!
}

\section{Questions?}

\author{
Comments?
}

\author{
Graham McCarthy \\ gmmcarthy@ryerson.ca \\ Sally Wilson \\ swilson@ryerson.ca
}

The very pretty images used in this presentation were provided by talented flickr users under Creative Commons use. Links to each image have been provided in the notes section of the presentation. 